
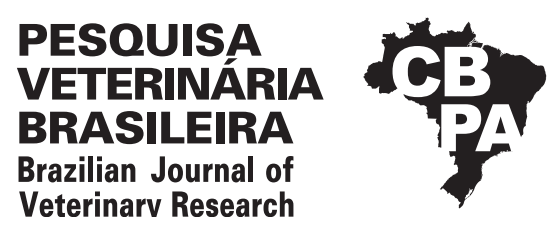

Pesq. Vet. Bras. 40(1):55-60, January 2020 DOI: 10.1590/1678-5150-PVB-6067

Veterinarv Research

ISSN 0100-736X (Print)

ISSN 1678-5150 (Online)

\title{
Clinical management of dogs with presumptive diagnosis of thoracolumbar intervertebral disc disease: 164 cases $(2006-2017)^{1}$
}

\author{
Raquel Baumhardt ${ }^{2}$, Angel Ripplinger ${ }^{3}$, Graciane Aiello ${ }^{3}$, Marcelo L. Schwab ${ }^{3}$, \\ Denis A. Ferrarin ${ }^{3}$, Mathias R. Wrzesinski ${ }^{3}$, Julia Rauber ${ }^{3}$ and Alexandre Mazzanti* ${ }^{*}$
}

\begin{abstract}
Baumhardt R., Ripplinger A., Aiello G., Schwab M.L., Ferrarin D.A., Wrzesinski M.R., Rauber J. \& Mazzanti A. 2020. Clinical management of dogs with presumptive diagnosis of thoracolumbar intervertebral disc disease: 164 cases (2006-2017). Pesquisa Veterinária Brasileira 40(1):55-60. Departamento de Clínica de Pequenos Animais, Centro de Ciências Rurais, Universidade Federal de Santa Maria, Av. Roraima 1000, Camobi, Santa Maria, RS 97105-900, Brazil. E-mail: alexamazza@yahoo.com.br

This study aimed to identify dogs with presumptive diagnosis of cervical intervertebral disc disease (IVDD) submitted to clinical management and to evaluate the outcomes. Data were obtained from the medical records of patients with neurological dysfunction assisted at a University Veterinary Hospital from 2006 to 2017. In addition to the patients' records, dog owners responded to a questionnaire on the success of therapy. Four hundred and thirteen neurological records were evaluated, and 164 met the inclusion criteria of the study. The most common breed was Dachshund, followed by mongrels. Classification of neurological dysfunction in the study sample was as follows: $15.9 \%$ with grade I, $25.6 \%$ with grade II, $26.8 \%$ with grade III, $8.5 \%$ with grade IV, and $23.2 \%$ with grade V. Outcome was satisfactory in $71.6 \%$ of the dogs and unsatisfactory in $28.4 \%$ of them. Recurrence was observed in $27.7 \%$ of those with satisfactory outcomes. The clinical treatment of dogs with thoracolumbar IVDD is satisfactory, particularly for animals with milder disease grades (I, II, and III). There is possibility of recurrence with conservative therapy and clinical signs may be more severe.
\end{abstract}

INDEX TERMS: Clinical management, dogs, diagnosis, thoracolumbar intervertebral, disc disease, rest, corticosteroids, NSAID, extrusion, protrusion.

\begin{abstract}
RESUMO.- [Tratamento clínico de cães com diagnóstico presuntivo de doença do disco intervertebral toracolombar: 164 casos (2006-2017).] 0 objetivo desse estudo foi identificar cães com diagnóstico presuntivo de DDIV toracolombar submetidos ao tratamento clínico, a fim de avaliar a resposta à terapia instituída. Foram revisados os registros neurológicos
\end{abstract}

\footnotetext{
${ }^{1}$ Received on March 12, 2019.

Accepted for publication on March 19, 2019.

${ }^{2}$ Serviço de Neurologia e Neurocirurgia Veterinária, Graduate Program in Veterinary Medicine, Medicina Veterinária, Centro de Ciências Rurais (CCR), Universidade Federal de Santa Maria (UFSM), Av. Roraima 1000, Camobi, Santa Maria, RS 97105-900, Brazil.

${ }^{3}$ Curso de Medicina Veterinária, Centro de Ciências Rurais (CCR), Universidade Federal de Santa Maria (UFSM), Av. Roraima 1000, Camobi, Santa Maria, RS 97105-900.

${ }^{4}$ Serviço de Neurologia e Neurocirurgia Veterinária, Departamento de Clínica de Pequenos Animais, Centro de Ciências Rurais (CCR), Universidade Federal de Santa Maria (UFSM), Av. Roraima 1000, Camobi, Santa Maria, RS 97105-900.*Corresponding author: alexamazza@yahoo.com.br
}

de cães atendidos pelo Serviço de Neurologia e Neurocirurgia Veterinária no período de 2006 a 2017 de um Hospital Veterinário Universitário. Foi realizada coleta de dados a partir dos registros e por meio de um questionário respondido pelos tutores. Foram avaliadas 413 fichas neurológicas de cães e obtidas informações para inclusão no estudo em 164 delas. As raças mais frequentes foram dachshunds, seguido de cães sem raça definida. Quanto ao grau de disfunção neurológica foi definido como grau I para $15,9 \%$ dos cães, grau II para $25,6 \%$, grau III para $26,8 \%$, grau IV para $8,5 \%$ e grau V para $23,2 \%$. A recuperação foi satisfatória em $71,6 \%$ dos cães e insatisfatória em $28,4 \%$. Dos que se recuperaram satisfatoriamente, $27,7 \%$ tiveram recidivas. Com base nos resultados obtidos pode-se concluir que o tratamento clínico em repouso absoluto e administração de anti-inflamatórios e analgésicos opióides para cães com DDIV toracolombar é efetivo, principalmente para cães em graus mais leves da doença (grau I, II e III). Há possibilidade de recidiva com esse tipo de terapia cujos sinais clínicos poderão ser mais graves. 
TERMOS DE INDEXAÇÃO: Tratamento clínico, cães, diagnóstico, doença do disco, intervertebral toracolombar, repouso, corticoide, AINE, extrusão, protrusão.

\section{INTRODUCTION}

Intervertebral disc disease (IVDD) is a common condition in the neurological clinic of dogs, and its most frequent site of occurrence is the thoracolumbar region (T3-L3) (Dewey \& Da Costa 2016). Dogs of chondrodystrophic breeds are the most affected, especially Dachshunds. There is no gender predisposition, and the average age varies between three and six years (Brisson 2010, Santos et al. 2012, Kranenburg et al. 2013).

Clinical signs range from spinal hyperesthesia to severe neurological disabilities such as loss of caudal nociception (deep pain) to injury (Sharp \& Wheeler 2005, Brisson 2010, Dewey \& Da Costa 2016).

Clinical treatment for IVDD is generally indicated for dogs with hyperesthesia associated or not with minimal neurological disabilities (Brisson 2010, Kranenburg et al. 2013, Dewey \& Da Costa 2016) and consists of absolute cage rest for four to six weeks (Sharp \& Wheeler 2005), assuming that this time would be the minimum required for fibrous annulus repair (Jerram \& Dewey 1999). Opioid analgesics, muscle relaxants, steroidal or nonsteroidal anti-inflammatory drugs (NSAID), and passive physical therapy are indicated, associated with rest (Sharp \& Wheeler 2005, Levine et al. 2007, Mann et al. 2007). Surgery is the treatment of choice for paraplegic dogs with or without nociception (Ferreira et al. 2002, Sharp \& Wheeler 2005, Dewey \& Da Costa 2016).

In contrast to the large number of retrospective studies addressing the efficacy of surgical treatment of dogs with thoracolumbar IVDD (Ferreira et al. 2002, Kazakos et al. 2005, Santos et al. 2012, Kranenburg et al. 2013, Jeffery et al. 2016), research evaluating the response to clinical treatment is scarce in the literature, especially nationally.

Therefore, the objective of this study was to identify dogs with presumptive diagnosis of thoracolumbar IVDD submitted to clinical treatment in order to evaluate the therapy outcomes and recurrence rates. This study also aimed to describe the age, sex, and response to treatment according to neurological grade, so that these parameters can be used as prognostic factors for the clinical evolution of these patients.

\section{MATERIALS AND METHODS}

Neurological records of dogs assisted at the Veterinary Neurology and Neurosurgery Service (SNNV) of a University Veterinary Hospital (HVU) from 2006 to 2017 were reviewed. Presumptive diagnosis was defined by history, breed, age, clinical signs, and neurological examination. All patients underwent imaging exams, namely, plain radiography (X-ray), myelography, or computed tomography $(\mathrm{CT})$, in order to discard other conditions such as discospondylitis, fractures, and neoplasms (Dewey \& Da Costa 2016). Serology was performed in all dogs to exclude probable infectious diseases (toxoplasmosis, neosporosis and distemper). Only dogs that presented a presumptive diagnosis of IVDD in the T3-L3 and L4-S3 segments of the spinal cord, and without other (non-neurological) diseases that could interfere with neurological evaluation were included in the survey.
Data were collected from the clinical and neurological records of patients and by telephone contact with owners. Dogs that underwent clinical treatment were selected for the study. Neurological dysfunction was classified from grades I to V, where grade I, only hyperesthesia; grade II, outpatient paraparesis; III grade, non-ambulatory paraparesis; grade IV, paraplegia with deep caudal pain perception; grade $\mathrm{V}$, paraplegia with absent deep caudal pain perception (Sharp \& Wheeler 2005). The dogs were distributed in age the following age groups: $\leq 3$ years; 4- 6 years; $7-9$ years, and $\geq 10$ years, according to the distribution by Chaves et al. (2014).

The clinical treatment prescribed to the dogs by the SNNV at the time of consultation consisted of absolute cage rest for at least 30 days, taken three times a day for urination and defecation with the use of a movement restriction guide associated with opioid analgesics and prednisone steroidal anti-inflammatory drug at a dose of $0.5-1.0 \mathrm{mg} / \mathrm{kg}$ every $24 \mathrm{~h}$ or nonsteroidal meloxicam at a dose of 0.1-0.2 mg/kg every $24 \mathrm{~h}$ (Dewey \& Da Costa 2016).

Owners responded to a two-part questionnaire: i) information before consultation and ii) information after consultation. Some information was obtained from the patients' medical records and supplemented with the owner's information at the time of the telephone contact.

Data from the first part of the questionnaire were related to the recurrence or not of clinical signs; duration of clinical signs until the time of consultation; use of anti-inflammatory drugs; absolute rest or maintenance in a confined space; evolution of clinical signs until the time of consultation. Recurrence was considered when there was previous history of dorsal pain and/or difficulty in walking or climbing obstacles. Duration of clinical signs was classified as follows: $\leq 1$ day; 2-7 days; 8-30 days; $>30$ days. Regarding the evolution of clinical signs, dogs were distributed as follows: improved - when there was an improvement compared with the onset of signs; stable - when no difference between the times was observed; progressive worsening - gradual worsening until the time of consultation; rapid worsening - paraplegia observed in less than five days.

Data from the second part of the questionnaire referred to the treatment indicated by the SNNV, administration of anti-inflammatory drugs, absolute rest or maintenance in a restricted space, and clinical evolution of treatment performed. Regarding the anti-inflammatory drug, it was asked whether it was steroidal (corticosteroid) or nonsteroidal (NSAID). Clinical evolution was classified as satisfactory - for dogs that recovered the ability to walk without hyperesthesia, and unsatisfactory - for those that did not recover motor function or remained with hyperesthesia. Dogs that had a satisfactory recovery were evaluated for the occurrence of disease recurrence.

Dogs whose owners opted for euthanasia or died within less than two weeks were excluded from the clinical evolution assessment. Dogs that presented paraplegia without deep pain perception (grade V) at the time of consultation and whose owners rated their recovery as satisfactory returned to the SNNV for further neurological examination to discard acquisition of involuntary spinal locomotion (spinal walking) (Gallucci et al. 2017).

The study sample was mainly composed of Dachshunds $59.1 \%(n=97)$. Other breeds included Poodle $(n=10)$, Pinscher $(n=3)$, Shih Tzu $(n=7)$, Lhasa Apso $(n=5)$, Pekingese $(n=4)$, Cocker Spaniel $(n=2)$, Beagle $(n=2)$, French Bulldog $(n=2)$, American Staffordshire Terrier $(n=1)$, Basset Hound $(n=1)$, Boxer $(n=1)$, Brazilian Mastiff $(n=1)$, Brazilian Terrier $(n=1)$, German 
Shepherd ( $\mathrm{n}=1)$, Pug $(\mathrm{n}=1)$, Schnauzer $(\mathrm{n}=1)$, and Yorkshire Terrier $(\mathrm{n}=1)$. The sample was included 23 mongrels. Age ranged from two to 15 years, and distribution was as follows: $13.4 \%$ $(n=22),>3$ years; $44.5 \%(n=73), 4-6$ years; $29.9 \%(n=49), 7-9$ years; $12.2 \%(\mathrm{n}=20), \geq 10$ years. Regarding gender, $43.9 \%(\mathrm{n}=72)$ were male and $56.1 \%(\mathrm{n}=92)$ female.

\section{RESULTS}

The survey identified 413 neurological records with a presumptive diagnosis of thoracolumbar and lumbar IVDD. Of these, 213 (51.5\%) owners responded to the telephone contact and agreed to answer the questionnaire and 164 confirmed clinical treatment was the first option. Of the latter, first-time presentation of clinical signs was observed in $80.5 \%$ ( $\mathrm{n}=132)$, recurrent (relapse) clinical signs were observed in $18.9 \%(\mathrm{n}=31)$, and $0.6 \%$ of the owners could not answer the question. In $65.9 \%(n=108)$ of these dogs, anti-inflammatory drugs were administered before the consultation, and $55.5 \%(\mathrm{n}=60)$ of them had received NSAID and corticosteroids, associated or not. In $26.2 \%(n=43)$ of the animals, anti-inflammatory drugs were not administered and $7.9 \%(n=13)$ of the owners could not answer the question. Of the dogs that received anti-inflammatory drugs, $70.4 \%$ presented worsening clinical signs $(n=53$ with progressive worsening and $\mathrm{n}=23$ with rapid worsening).

Regarding gender, $70.6 \%$ of the females and $70.8 \%$ of the males showed satisfactory recovery. In the age groups, $75 \%$ of the dogs aged $<3$ years, $65.1 \%$ of those aged $4-6$ years, $79.6 \%$ of those aged $7-9$ years, and $80 \%$ of the animals aged $\geq 10$ years presented satisfactory recovery.

As for the evolution of clinical signs and treatment prior to consultation, absolute cage rest was observed in $12.2 \%$ $(n=20)$ of the dogs, $27.4 \%(n=45)$ of the animals rested in restricted spaces, and $60.4 \%(\mathrm{n}=99)$ of them did not rest at all. Clinical signs improved in $9.7 \%(\mathrm{n}=16)$, remained stable in $17.1 \%(\mathrm{n}=28)$, progressively worsened in $50.6 \%(\mathrm{n}=83)$, and rapidly worsened in $22.6 \%(\mathrm{n}=37)$ of the dogs. Neurological dysfunction was classified as grade I in $15.9 \%(\mathrm{n}=26)$, grade II in $25.6 \%(\mathrm{n}=42)$, grade III in $26.8 \%(\mathrm{n}=44)$, grade IV in $8.5 \%$ $(\mathrm{n}=14)$, and grade $\mathrm{V}$ in $23.2 \%(\mathrm{n}=38)$ of the animals.

When neurological dysfunction was distributed according to the rest performed prior to the consultation, $85.7 \%$ of the dogs with milder disease grades (I and II) and that underwent absolute cage rest showed improvement of clinical signs or remained stable. When rest occurred in restricted spaces, $42.9 \%$ and $37.5 \%$ of the dogs with grades I and II of neurological dysfunction presented worsening of clinical signs, respectively; and when no rest occurred, $56.2 \%$ and $66.7 \%$ of the dogs with grades I and II of neurological dysfunction showed worsening of clinical signs. Of the dogs with grade III, $22.2 \%$ of those that had absolute cage rest improved, $22.2 \%$ remained stable, and the others had worsening signs. Of those that rested in restricted spaces, $100 \%$ showed worsened clinical signs, and those that did not rest at all, $18.5 \%$ remained stable and $81.5 \%$ presented worsened clinical signs. All dogs with grades IV and V of neurological dysfunction, regardless of the occurrence of rest, presented worsened clinical signs, except for one dog with grade $V$, which remained stable (Table 1 ).

Of the total number of dogs with clinical treatment prescribed by the SNNV, 85.6\% ( $\mathrm{n}=141)$ of the owners agreed to perform the therapy on the day of consultation. Clinical evolution (Table 2) was satisfactory in $71.6 \%(\mathrm{n}=101)$ and unsatisfactory in $28.4 \%(\mathrm{n}=40)$ of the animals. Of those with satisfactory recovery, 76 (75.3\%) underwent absolute cage rest, 19 (18.8\%) rested in restricted spaces restriction, and six (5.9\%) did not rest at all.

As for unsatisfactory recovery, 25 dogs $(62.5 \%)$ were under absolute cage rest, $11(27.5 \%)$ rested in restricted spaces, and four (10\%) did not rest at all (owners' option). Disease recurrence was observed in $28(27.7 \%)$ dogs: $25 \%$ $(n=7)$ of those had more severe clinical signs, $46.4 \%(n=13)$ showed similar signs, and $6 \%(\mathrm{n}=8)$ presented milder signs.

Duration of clinical signs was $\leq 1$ day in $9.2 \%(n=13)$, 2-7 days in $39.0 \%(n=55), 8-30$ days in $41.2 \%(n=58)$, and $>30$ days in $10.6 \%$ ( $n=15$ ) of the dogs. Most of the animals with clinical signs lasting up to 30 days recovered satisfactorily $(<1$ day $=76.9 \% ; 2-7$ days $=76.4 \% ; 8-30$ days $=70.7 \%$ ). Only $53.3 \%$ of the dogs with clinical signs lasting $>30$ days presented satisfactory recovery.

Of the 141 dogs that should undergo clinical treatment as prescribed by the SNNV, absolute cage rest was observed in $62.3 \%(\mathrm{n}=102)$. In 30 dogs $(21.3 \%)$, rest occurred in restricted spaces, and nine (6.4\%) animals did not rest at all. Recovery was satisfactory in 88.0 , and $80.5 \%$ for dogs with grvII of neurological dysfunction, respectively. Of the dogs

Table 1. Evolution of clinical signs in relation to pre-consultation treatment and neurological grade of 164 dogs with presumptive diagnosis of thoracolumbar IVDD

\begin{tabular}{|c|c|c|c|c|c|}
\hline $\begin{array}{l}\text { Previous } \\
\text { treatment }\end{array}$ & $\begin{array}{c}\text { Total } \\
\mathrm{n}\end{array}$ & $\begin{array}{c}\text { Improved } \\
\mathrm{n}\end{array}$ & $\begin{array}{c}\text { Stable } \\
\mathrm{n}\end{array}$ & $\begin{array}{c}\text { Progressive } \\
\text { worsening } \\
\mathrm{n}\end{array}$ & $\begin{array}{c}\text { Rapid } \\
\text { worsening } \\
\mathrm{n}\end{array}$ \\
\hline Grade I & 25 & 3 & 10 & 12 & - \\
\hline Rest AB & 2 & 1 & 1 & - & - \\
\hline Rest RS & 7 & - & 4 & 3 & - \\
\hline Without rest & 16 & 2 & 5 & 9 & - \\
\hline Grade II & 42 & 11 & 10 & 21 & - \\
\hline Rest AB & 5 & 3 & 1 & 1 & - \\
\hline Rest RS & 16 & 7 & 3 & 6 & - \\
\hline Without rest & 21 & 1 & 6 & 14 & - \\
\hline Grade III & 45 & 2 & 7 & 35 & 1 \\
\hline Rest AB & 9 & 2 & 2 & 5 & - \\
\hline Rest RS & 9 & - & - & 9 & - \\
\hline Without rest & 27 & - & 5 & 21 & 1 \\
\hline Grade IV & 14 & - & - & 5 & 9 \\
\hline Rest AB & 1 & - & - & - & 1 \\
\hline Rest RS & 4 & - & - & 2 & 2 \\
\hline Without rest & 9 & - & - & 3 & 6 \\
\hline Grade V & 38 & - & 1 & 10 & 27 \\
\hline Rest AB & 3 & - & - & - & 3 \\
\hline Rest RS & 9 & - & - & 3 & 6 \\
\hline Without rest & 26 & - & 1 & 7 & 18 \\
\hline $\mathrm{AI}$ & 108 & 13 & 19 & 53 & 23 \\
\hline Without AI & 42 & 3 & 6 & 23 & 10 \\
\hline CNA & 14 & - & 3 & 7 & 4 \\
\hline TOTAL & 164 & 16 & 28 & 83 & 37 \\
\hline
\end{tabular}

$\mathrm{n}=$ number of dogs; $\mathrm{AB}=$ absolute; $\mathrm{RS}=$ restricted space; $\mathrm{AI}=$ anti-inflammatory drugs; CAN = could not answer. 
Table 2. Clinical evolution regarding clinical treatment outcome and neurological grade of the 141 dogs with presumptive diagnosis of thoracolumbar IVDD

\begin{tabular}{|c|c|c|c|}
\hline & $\begin{array}{c}\text { Number of } \\
\text { dogs } \\
n=141\end{array}$ & $\begin{array}{c}\text { Unsatisfactory } \\
\text { recovery } \\
\text { n }\end{array}$ & $\begin{array}{c}\text { Satisfactory } \\
\text { recovery } \\
\text { n }\end{array}$ \\
\hline \multicolumn{4}{|l|}{ Sex } \\
\hline Female & 80 & 22 & 58 \\
\hline Male & 61 & 18 & 43 \\
\hline \multicolumn{4}{|l|}{ Age } \\
\hline$<3$ years & 19 & 5 & 14 \\
\hline $4-6$ years & 69 & 24 & 45 \\
\hline $7-9$ years & 37 & 8 & 29 \\
\hline$>10$ years & 16 & 3 & 13 \\
\hline \multicolumn{4}{|c|}{ Duration of clinical signs } \\
\hline$<1$ day & 13 & 4 & 9 \\
\hline 2-7 days & 55 & 14 & 41 \\
\hline 8-30 days & 58 & 16 & 42 \\
\hline$>30$ days & 15 & 7 & 8 \\
\hline \multicolumn{4}{|l|}{ Rest } \\
\hline Absolute & 102 & 26 & 76 \\
\hline Restricted space & 30 & 11 & 19 \\
\hline Without rest & 9 & 3 & 6 \\
\hline \multicolumn{4}{|c|}{ Neurological dysfunction } \\
\hline Grade I & 25 & 3 & 22 \\
\hline Grade II & 40 & 8 & 32 \\
\hline Grade III & 41 & 8 & 33 \\
\hline Grade IV & 12 & 6 & 6 \\
\hline Grade V & 23 & 15 & 8 \\
\hline TOTAL & 141 & 40 & 101 \\
\hline
\end{tabular}

with grades IV and V, $50.0 \%$ and $34.8 \%$ showed satisfactory recovery, respectively.

Of the 141 dogs, $111(78.7 \%)$ received anti-inflammatory drugs prescribed by the SNNV, $62.4 \%(n=88)$ were treated with corticosteroids, and $16.3 \%(\mathrm{n}=23)$ received NSAID. Of the dogs receiving corticosteroids, $70.5 \%(n=62)$ had satisfactory recovery, and $78.3 \%(n=18)$ of those receiving NSAID recovered satisfactorily. Twenty-four (17.0\%) dogs were not prescribed with anti-inflammatory drugs by the SNNV; however, they had already received medication for the time recommended before the consultation and, therefore, only opioid analgesic was prescribed.

\section{DISCUSSION}

Prevalence of gender, age, and breed of the patients studied is similar to that reported in previously published studies (Levine et al. 2007, Brisson 2010, Kranenburg et al. 2013).

Recovery of dogs in the different age groups had similar proportions, suggesting that there was no interference of age in this variable, corroborating the findings of previous studies (Olby et al. 2004, Penning et al. 2006); however, some authors have reported better (Macias et al. 2002, Levine et al. 2007) and faster (Olby et al. 2003) recovery in young dogs. Variation in methodology and difference in study samples sizes may have interfered with divergent results.
Male and female dogs had similar recovery times, in agreement with the results found by Macias et al. (2002), who found no gender influence on recovery. Experimental studies have described that the female hormone would have a neuroprotective effect (Marchetti et al. 2000, Bjorling et al. 2002), and retrospective studies have found higher occurrence of IVDD in male dogs (Ferreira et al. 2002, Penning et al. 2006). A population study of the region is essential to conclude about gender predisposition in IVDD.

According to Levine et al. (2007), duration of clinical signs was significant for therapeutic response in dogs treated clinically for thoracolumbar IVDD. The studies by Ferreira et al. (2002), Macias et al. (2002), Olby et al. (2003), Kazakos et al. (2005) have demonstrated that the duration of clinical signs until treatment did not influence the patients' recovery. In this study, the duration of clinical signs up to 30 days did not seem to influence clinical evolution; however, when compared with dogs with that presented signs for $>30$ days, worse recovery results were observed.

There was indication of surgery for all grade IV dogs $(\mathrm{n}=14)$ and for seven grade $\mathrm{V}$ animals. However, two dogs with grade IV and five with grade $V$ neurological dysfunction were euthanized on the owners' choice. Santos et al. (2012) reported that some of these paraplegic dogs might show satisfactory recovery in the long term. In the present study, $34.7 \%$ of the dogs with grade $V$ that underwent clinical treatment presented satisfactory recovery. Although $65.3 \%$ of the dogs with grade $V$ did not recover with treatment, five developed spinal walking, considered by most owners as satisfactory recovery. Owners should be advised that there is a possibility of motor function recovery even without recovering from nociception. In a retrospective study, Gandini et al. (20017) found that of the 81 paraplegic dogs without deep pain perception, $59 \%(n=49)$ developed spinal walking, and that intense physical therapy enabled dogs to acquire this type of involuntary movement. They also noted that young and lightweight dogs were more likely to develop spinal walking.

In grades I and II of neurological dysfunction, absolute cage rest prior to the consultation allowed most dogs to recover a clinical condition better than that observed at the onset of clinical signs, or to remain with stable signs. For those that did not rest before the consultation, at all neurological dysfunction grades, $79.8 \%$ arrived at the SNNV with worsening clinical signs (Table 1). Clinical treatment outcomes were as follows: of the 102 dogs that underwent absolute cage rest, 76 (74.5\%) had satisfactory recovery, showing that dogs kept in cages or transport boxes are 2.5 times more likely to respond better to treatment (Table 2) compared with those that rested in restricted spaces or did not rest at all.

Cage rest for approximately four to six weeks is indicated for the satisfactory recovery of dogs treated for IVDD due to healing of ligamentous structures, lower chance of extrusion of the nucleus pulposus, and reduced likelihood of accidental traumatic injury (Sharp \& Wheeler 2005, Dewey \& Da Costa 2016). Although Levine et al. (2007) did not observe a relationship between clinical improvement of patients and duration of cage rest when comparing resting with non-resting dogs, they found that those that rested presented a 1.6-time greater chance of successful recovery. Based on these results, they suggested that resting is associated with better recovery, 
but that absolute restriction of exercise over extended periods in dogs with IVDD is not ensured by treatment with medications.

Approximately $65.9 \%$ of the dogs in this study received anti-inflammatory drugs before the consultation, and $70.4 \%$ of these presented worsening of clinical signs. In addition, $87.8 \%$ of the dogs did not undergo absolute cage rest. These results suggest that only anti-inflammatory drugs may not be sufficient for satisfactory evolution, as they do not act on the dynamic component of the disease. The effects of NSAID and corticosteroids may decrease the discomfort of patients with spinal cord disease and encourage them to excessive activity (Platt et al. 2005).

The results obtained with respect to recovery and recurrence of neurological signs were similar to those found by Levine et al. (2007), who justified their satisfactory results with the fact that most dogs presented milder grades of neurological dysfunction (I, II and III). In this study, dogs with grades I, II, and III showed better therapeutic response compared with that of dogs with grades IV and V, suggesting that clinical treatment is satisfactory is for milder disease grades.

Corticosteroids are useful in the treatment of vasogenic edema of the spinal cord (Kraus 1996). However, their use in IVDD has been questioned both for their effectiveness in treatment (Levine et al. 2007, Mann et al. 2007) and for the decreased resulting quality of life, which is better in dogs that receive NSAID (Levine et al. 2007). In the present study, recovery in dogs receiving NSAID or corticosteroids was similar, but this assessment was impaired because of the relatively larger number of animals that had received anti-inflammatory drugs before the first consultation.

Mann et al. (2007) associated the use of corticosteroids with higher recurrence rate when compared with the use of NSAID. Thus, these authors suggest that the use of corticosteroids may influence the healing of the fibrous annulus of the intervertebral disc, contributing to recurrence in the same site, or on different disks owing to the adverse effects of collagen synthesis and degradation, especially if the disc is already undergoing a degenerative process. No higher recurrence rates were observed in the group receiving corticosteroids.

One of the limitations to this study was the presumptive and indefinite diagnosis of IVDD. Levine et al. (2007) used plain radiography and myelography as diagnostic methods to exclude other causes such as discospondylitis, meningomyelitis, fractures, and neoplasms. In this study, in addition to myelography and plain radiography, CT was performed, which is considered an imaging examination with sensitivity superior to that of myelography in detecting spinal cord compression caused by IVDD (Brisson 2010). Even so, magnetic resonance imaging (MRI) is used for the definite diagnosis of IVDD and, more precisely, surgical explorations that will reveal the extruded content inside the vertebral canal (Levine et al. 2007). Therefore, the possibility that some dogs in this study with presumptive diagnosis of IVDD had another neurological disorder cannot be discarded.

The clinical relevance of this research was to demonstrate the results of clinical treatment of dogs with presumptive diagnosis of thoracolumbar IVDD in Brazil and to verify whether recovery rate was satisfactory mainly in dogs with milder (I, II and III) and more severe (IV and V) neurological dysfunction grades. This type of therapy was not effective, and surgical decompression was recommended immediately
(Dewey \& Da Costa 2016). Regarding recurrence, the results found were similar to those described in the international literature (Levine et al. 2007). The clinical therapy employed in this study, with absolute cage rest, was as recommended in the literature (Dewey \& Da Costa 2016) and promoted satisfactory recovery in most patients. Owners who did not follow the instructions of the SNNV and opted for rest in restricted spaces, also obtained satisfactory results, but in a smaller number of cases (Table 1).

\section{CONCLUSIONS}

Clinical treatment with absolute cage rest and administration of anti-inflammatory drugs and opioid analgesics for dogs with thoracolumbar IVDD is effective, especially for dogs with milder disease levels (grades I, II, and III).

There is possibility of recurrence with conservative therapy using nonsteroidal anti-inflammatory drugs (NSAID), and clinical signs may be more severe. No change in response between dogs of different age or sex was observed, suggesting that there is no prognostic influence of these factors on recovery.

Acknowledgments.- This study was supported by the "Conselho Nacional de Desenvolvimento Científico e Tecnológico" (CNPq), process no. 307120/2017-1, and "Coordenação de Aperfeiçoamento de Pessoal de Nível Superior" (CAPES).

Conflict of interest statement.- The authors declare having no competing interests.

\section{REFERENCES}

Bjorling D.E., Beckman M., Clayton M.K. \& Wang Z.-Y. 2002. Modulation of nerve growth factor in peripheral organs by estrogen and progesterone. Neuroscience 110(1):155-167. <http://dx.doi.org/10.1016/S03064522(01)00568-1><PMid:11882380>

Brisson B.A. 2010. Intervertebral disc disease in dogs. Vet. Clin. N. Am. Small Anim. Pract. 40(5):829-858. <http://dx.doi.org/10.1016/j.cvsm.2010.06.001> <PMid:20732594>

Chaves R.O., Beckmann D.V., Santos R.P., Aiello G., Andrades A.O., Baumhardt R., Silveira L.B.\& Mazzanti A. 2014. Doenças neurológicas em cães atendidos no Hospital Veterinário da Universidade Federal de Santa Maria, RS: 1.184 casos (2006-2013). Pesq. Vet. Bras. 34(10):996-1001. <http://dx.doi. org/10.1590/S0100-736X2014001000012>

Dewey C. \& Da Costa R.C. 2016. Myelopathies: disorders of the spinal cord, p.329-403. In: Ibid. (Eds), Practical Guide to Canine and Feline Neurology. 3rd ed. Wiley Blackwell, Ames.

Ferreira A.J.A., Correia J.H.D. \& Jaggy A. 2002. Thoracolumbar disc disease in 71 paraplegic dogs: influence of rate of onset and duration of clinical signs on treatment results. J. Small Anim. Pract. 43(4):158-163. <http:// dx.doi.org/10.1111/j.1748-5827.2002.tb00049.x> <PMid:11996392>

Gallucci A., Dragone L., Menchetti M., Gagliardo T., Pietra M., Cardinali M. \& Gandini G. 2017. Acquisition of involuntary spinal locomotion (spinal walking) in dogs with irreversible thoracolumbar spinal cord lesion: 81 dogs. J. Vet. Intern. Med. 31(2):492-497. <http://dx.doi.org/10.1111/ jvim.14651> <PMid:28238221>

Jeffery N.D., Barker A.K., Hu H.Z., Alcott C.J., Kraus K.H., Scanlin E.M., Granger N. \& Levine J.M. 2016. Factors associated with recovery from paraplegia in dogs with loss of pain perception in the pelvic limbs following intervertebral disk herniation. J. Am. Vet. Med. Assoc. 248(4):386-394. <http://dx.doi. org/10.2460/javma.248.4.386> <PMid:26829270>

Jerram R.M. \& Dewey C.W. 1999. Acute thoracolumbar disk extrusion in dogs - part II. Compend. Contin. Educ. Pract. Vet. 21(11):1037-1047. 
Raquel Baumhardt et al.

Kazakos G., Polizopoulou Z.S., Patsikas M.N., Tsimopoulos G., Roubies N. \& Dessiris A. 2005. Duration and severity of clinical signs as prognostic indicators in 30 dogs with thoracolumbar disk disease after surgical decompression. J. Vet. Med. 52(3):147-152. <http://dx.doi.org/10.1111/j.1439-0442.2005.00698. x> <PMid:15836447>

Kranenburg H.J., Grinwis G.C., Bergknut N., Gahrmann N., Voorhout G., Hazewinkel H.A. \& Meij B.P. 2013. Intervertebral disc disease in dogs - part 2: comparison of clinical, magnetic resonance imaging, and histological findings in 74 surgically treated dogs. Vet. J. 195(2):164-171. <http:// dx.doi.org/10.1016/j.tvjl.2012.06.001> <PMid:22795604>

Kraus K.H. 1996. The pathophysiology of spinal cord injury and its clinical implications. Semin. Vet. Med. Surg. 11(4):201-207. <PMid:9020573>

Levine J.M., Levine G.J., Johnson S.I., Kerwin S.C., Hettlich B.R. \& Fosgate G.T. 2007. Evaluation of the success of medical management for presumptive thoracolumbar intervertebral disk herniation in dogs. Vet. Surg. 36(5):482-491. <http://dx.doi.org/10.1111/j.1532-950X.2007.00295.x><PMid:17614930>

Macias C., McKee W.M., May C. \& Innes J.F. 2002. Thoracolumbar disc disease in large dogs: a study of 99 cases. J. Small Anim. Pract. 43(10):439-446. <http://dx.doi.org/10.1111/j.1748-5827.2002.tb00010.x><PMid:12400641>

Mann F.A., Wagner-Mann C.C., Dunphy E.D., Ruben D.S., Rochat M.C. \& Bartels K.E. 2007. Recurrence rate of presumed thoracolumbar intervertebral disc disease in ambulatory dogs with spinal hyperpathia treated with anti-inflammatory drugs: 78 cases (1997-2000). J. Vet. Emerg. Crit. Care 17(1):53-60. <http://dx.doi.org/10.1111/j.1476-4431.2006.00195.x>

Marchetti B., Gallo F., Farinella Z., Tirolo C., Testa N., Caniglia S. \& Morale M.C. 2000. Gender, neuroendocrine-immune interactions and neuron-glial plasticity: role of luteinizing hormone-releasing hormone (LHRH). Ann. N. Y.
Acad. Sci. 917(1):678-709. <http://dx.doi.org/10.1111/j.1749-6632.2000. tb05434.x> <PMid:11268397>

Olby N., Levine J., Harris T., Muñana K., Skeen T. \& Sharp N. 2003. Longterm functional outcome of dogs with severe injuries of the thoracolumbar spinal cord: 87 cases (1996-2001). J. Am. Vet. Med. Assoc. 222(6):762-769. <http://dx.doi.org/10.2460/javma.2003.222.762> <PMid:12675299>

Olby N., Harris T., Burr J., Muñana K., Sharp N. \& Keene B. 2004. Recovery of pelvic limb function in dogs following acute intervertebral disc herniations. J. Neurotrauma 21(1):49-59. <http://dx.doi.org/10.1089/089771504772695940> <PMid:14987465>

Penning V., Platt S.R., Dennis R., Cappello R. \& Adams V. 2006. Association of spinal cord compression seen on magnetic resonance imaging with clinical outcome in 67 dogs with thoracolumbar intervertebral disc extrusion. J. Small Anim. Pract. 47(11):644-650. <http://dx.doi. org/10.1111/j.1748-5827.2006.00252.x><PMid:17076787>

Platt S.R., Abramson C.J. \& Garosi L.S. 2005. Administering corticosteroids in neurologic diseases. Compend. Contin. Educ. Pract. Vet. 10:210-219.

Santos R.P., Beckmann D.V., Aiello G., Berté L., Ripplinger A., Polidoro Neto D. \& Mazzanti A. 2012. Recuperação funcional de cães paraplégicos com doença do disco intervertebral toracolombar sem percepção à dor profunda submetidos ao tratamento cirúrgico: 15 casos (2006-2010). Pesq. Vet. Bras. 32(3):243-246. <http://dx.doi.org/10.1590/S0100-736X2012000300011>

Sharp N.J.H. \& Wheeler S.J. 2005. Thoracolumbar disc disease, p.121-159. In: Ibid. (Eds), Small Animal Spinal Disorders: Diagnosis And Surgery. 2nd ed. Elsevier, Scotland. <http://dx.doi.org/10.1016/B978-0-72343209-8.50012-1>. 